\title{
HOW TO PRESENT 'FINANCIAL HEALTH' ANALYSIS MORE VISUAL AND UNDERSTANDABLE FOR STAKEHOLDERS: MODEL, CONFIGURATION, TECHNIQUES
}

\author{
Svitlana Kuznetsova \\ Alfred Nobel University, Ukraine \\ Andriy Kuznetsov \\ Alfred Nobel University, Ukraine
}

\begin{abstract}
In the last thirty years set of financial and non-financial indicators to measure the companies' health and prospects of grow rapidly. Reporting expands and changes in the direction of the introduction of non-financial information. Integrated reporting is seen as a necessary form of presentation of information about the company. This consequently leads to the transformation of the financial statements. The increase of information flows in society, and expanding range of statements users require modification tools for financial statement analysis in the direction of comprehensive and visual presentation of the results especially graphically.

The aim of this paper is to develop financial statement analysis in way of comprehensive measurement of financial health, and use benchmark assessment as an element of financial statement analysis through determination and investigation of current financial health configuring.
\end{abstract}

Keywords: financial statement, financial analysis, assessment, financial health

JEL code: M41

\section{Introduction}

Financial statements traditionally considered as the universal language of business. It is the primary resource for financial decision-making. In this direction the financial statement analysis is used as an effective tool for assessing the state of affairs in the company.

Two main streams of literature have analyzed this topic in contemporary financial statement analysis research. The continuing interest in financial statement analysis primarily stems from financial ratios analyses (see Cochran and Wood, 1984; Gibson, 1990; Desai et al., 2015; Han and Chen, 2014; Stickney et al., 1990; Zheng and Alver, 2015; Ohlson, 1980; Vogel, 2014), which include discriminant analysis. Moreover, a large number of theoretical and empirical works argue that theory is that ratios, if analyzed within a multivariate framework, will take on greater statistical significance than the common technique of sequential ratio comparisons (see Altman, 1968; Deakin, 1972).

In contrast, scholars in the field of valuation of companies using financial statement analysis as assessment tool for valuation of business growth and its prospects in various aspects (see Li and Mohanram, 2014; Kaplan and Norton, 1996; Penman and Penman, 2007; Schmidlin, 2014; Yermack, 1996). Furthermore, they suggest that a comprehensive assessment financial ratio predicts 'financial health' (Barth et al., 1998; Edmister, 1972; Lewellen, 2004; Ross, 1977; Al Mamun, 2013).

The development and increasing complexity of business and society require corresponding change in the statements. Thus, globalization and integration have caused the development of international financial reporting (see Alver and Alver, 2008; Christensen et al., 2015; Horton et al., 2013; Maystadt, 2013). The increase in the information flows through the development of IT-technology allows on the one hand expanding the range of users (stakeholders) and on 
the other hand leads to an increase in financial and non-financial indicators to measure the companies' health and prospects of grow. An example is the integrated reporting, in which the financial statements occupy only as part of it.

IFRS lays down conditions to the financial information that appears in the financial statements, including in particular - understandable. So, the growing number of stakeholders and indicators require transformation of the financial statement analysis in the direction of a comprehensive and integrated analysis and visual presentation of its results in relatively simple configuration.

Our research is aimed at comprehensive measurement of 'financial health' within financial statement analysis in order the design 'financial health' assessment truth the determination and investigation of current 'financial health' configuring.

The reminder of the paper is structured as follows. Section 2 describes the theoretical framework particularly research method, specific functions, methods, and techniques, while Section 3 presents building of 'financial health' configuration quantitatively and graphically by different financial points (types of ratios). Finally, Section 4 provides conclusions, advantages of the study and implications for further research.

\section{Theoretical framework}

The proposal of this paper is to fill the gaps mentioned above by realizing limited results of the financial statement analysis theoretical models, which eliminate comprehensive measurement of financial health in order to design benchmark assessment as an element of financial statement analysis through determination and investigation of current financial health configuring. The result of implementation of this assessment instrument must be in finding an answer to the central research question within each observed company: how preferred financial health configuration corresponds with the current one in company? To make this model effective and efficient, it must be determined specific functions, methods, and techniques.

The basis for Financial Statement Assessment Instrument should put Organizational Culture Assessment Instrument (OCAI) proposed by Cameron and Quinn (2005, 2011). In support of this choice the following arguments are demonstrated. Firstly, use of OCAI is aimed at profiling organizational culture based on valuesdetermined by the designed framework and provides assessment of organizational culture within the four types of organizational values: clan, adhocracy, market, and bureaucracy. Various financial ratios, which are represented in Table 1, show that similar approach of financial statement analyses are formed by financial values. Therefore, OCAI can be improved in the context of its use for evaluating types of financial health. Secondly, OCAI has several advantages which are crucial for building financial statement analyses model including: practical orientation, timeliness, extent of involvement, access to management, and validity.

Given this scientific background, the FSAI functions represented in Figure 1 can be derived. 


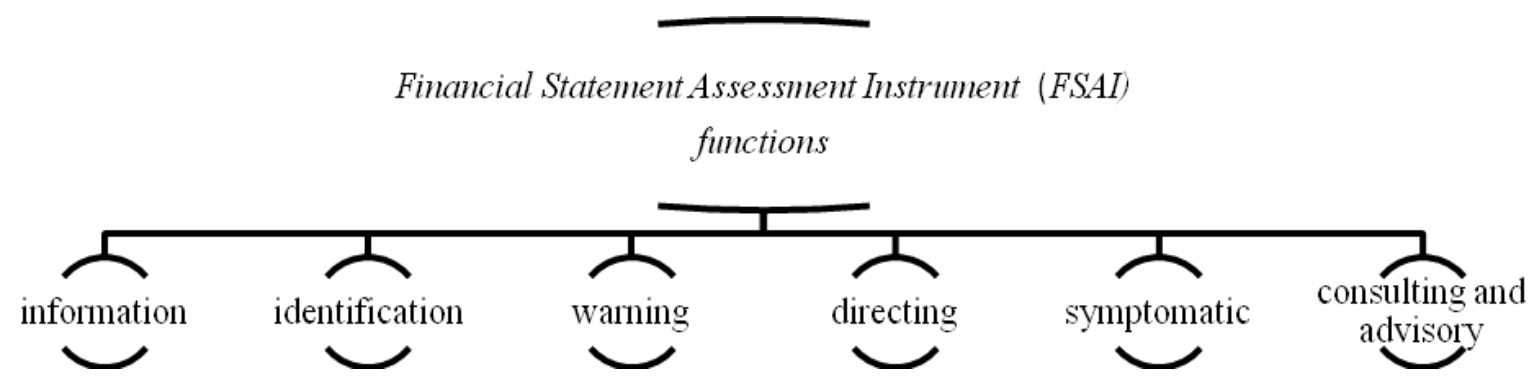

Figure 1. Functions of Financial Statement Assessment Instrument (FSAI). Source: Adopted from Cameron and Quinn 2011

The information function provides permanent or systematic collection of information about the form of financial health in the company from various sources, its detailed elaboration by components (types of management activities, responsibility centers, and managers), systematization, and grouping, summarizing and providing for the optimization of financial decisions as a whole.

The identification function means identification of the existing current, retrospective and predictive financial configuring, determining their characteristic features, advantages and disadvantages and matching the overall mission of the company.

The warning function involves evaluation of the prerequisites for changes in 'financial health' configuration and is aimed at identifying possible risks and threats in the current period and predicting potential crises in the future in the context of compliance of current 'financial health' configuration (including corresponding accounts) with the existing ideas and needs of the enterprise.

The directing function is designed to help eliminate identified deficiencies, deviations, existing problems and develop appropriate measures for the relevant detailed profiles, based on the obtained results and evaluation aimed at improving 'financial health' configuring.

The symptomatic function involves detection and interpretation of the 'symptoms' of current 'financial health' configuration to determine whether this form is optimal in comparison with the preferred one detailing the relevant profiles.

The various financial ratios could be structured according to different classification criteria (see Gibson, 1990; Desai et al., 2015; Han and Chen, 2014; Li and Mohanram, 2014; Penman and Penman, 2007; Schmidlin, 2014; Stickney et al., 1990). Given this scientific background, we have summarized these financial ratios to six groups: Liquidity; Profitability; Financial leverage (debt); Valuation and Growth; Activity (Management Efficiency); Coverage, which are represented in Table 1. 
Table 1. Grouping of financial ratios

\begin{tabular}{|lll|}
\hline \multicolumn{2}{|c|}{ Types of ratios } & \multicolumn{1}{c|}{ Financial ratios } \\
\hline 1. & Liquidity ratios & Current Ratio; Acid Test (Quick) Ratio; Cash Ratio \\
2. & Profitability ratios & $\begin{array}{l}\text { Gross Profit Ratio; Return on Sales; Return on Assets; Return on } \\
\text { Stockholders' Equity }\end{array}$ \\
3. & Financial leverage (debt) ratios & Debt-Equity Ratio; Equity Ratio; Debt Ratio; Times Interest Earned \\
4. & Valuation and Growth ratios & $\begin{array}{l}\text { Earnings per Share; Price-Earnings Ratio; Dividend Pay-out Ratio; } \\
\text { Dividend Yield Ratio; Book Value per Share }\end{array}$ \\
5. & $\begin{array}{l}\text { Activity (Management } \\
\text { Efficiency) ratios }\end{array}$ & $\begin{array}{l}\text { Receivable Turnover; Inventory Turnover; Accounts Payable } \\
\text { Turnover; Total Asset Turnover } \\
\text { Times interest earned ratio; Fixed charge coverage ratio; Debt }\end{array}$ \\
6. & Coverage ratios & service coverage ratio
\end{tabular}

Thus, evaluating the Financial Statement Assessment Instrument involves the construction of financial health configuration investigated on the basis of preliminary evaluation of financial points by 24 financial ratios.

The consulting and advisory function of the assessment instrument of 'financial health' configuration involves consideration of multiple alternative measures that may be developed to address the problem of the efficiency of 'financial health' configuration of the company.

Procedure of 'financial health' configuration assessment includes 13 steps:

Step 1. Determining the subjects of evaluation.

Step 2. Assessment of current 'financial health' by 24 financial ratios.

Step 3. Construction of the current 'financial health' profiles on current types of 'financial health' by 6 classification criteria.

Step 4. Interpretation of 6 current 'financial health' profiles.

Step 5. Construction of the current 'financial health' configuring.

Step 6. Interpretation of current 'financial health' configuring.

Step 7. Assessment preferred types of 'financial health' by 6 classification criteria.

Step 8. Construction preferred 'financial health' profiles on current types of 'financial health' by 6 classification criteria.

Step 9. Interpretation 6 desirable 'financial health' profiles.

Step 10. Construction of preferred 'financial health' configuration.

Step 11. Interpretation of preferred 'financial health' configuration.

Step 12. Comparative analysis of the current and preferred 'financial health' configuration.

Step 13. Evaluation preconditions changing 'financial health' configuring.

As already mentioned, our Financial Statement assessment instrument is based on the use of the mathematical method of investigation.

To calculate the total of ratings Table 2 has been used. It is necessary to fill separate entries of assessment results for the existing types and separately - for the preferred types of 'financial health' configuring. 
Table 2. Calculation of ratings for overall Financial Statement Assessment Instrument surveys for each period

The period measured: current/preferred (cross out unnecessary)

\begin{tabular}{|c|c|c|c|c|c|}
\hline \multirow[t]{2}{*}{ Types of ratios } & & & & \multirow[b]{2}{*}{$\mathrm{D}$} & \multirow[b]{2}{*}{$\mathrm{E}$} \\
\hline & A & $\mathrm{B}$ & $\mathrm{C}$ & & \\
\hline Liquidity ratios & & & & $\mathrm{x}$ & $\mathrm{x}$ \\
\hline Profitability ratios & & & & & $\mathrm{x}$ \\
\hline Financial leverage (debt) ratios & & & & & $\mathrm{x}$ \\
\hline Valuation and Growth ratios & & & & & \\
\hline Activity (Management Efficiency) ratios & & & & $\mathrm{x}$ & $\mathrm{x}$ \\
\hline Coverage ratios & & & & & \\
\hline
\end{tabular}

The next step is evaluation of 'financial health' configuration to determine the mean estimates for each profile of 'financial health' of the company. This step is performed when more than one period has been involved.

This includes the scores for each alternative on each issue and then dividing this sum by the number of periods:

$$
\overline{O q a}=\frac{\sum_{i=1}^{n} \text { Oqai }}{n},
$$

where $\overline{O q a}$ - the average score for a-alternative and q-profile of 'financial health' of the enterprise;

$a$ - the alternative for which the average score is calculated;

$q$ - question which is determined by the type of 'financial health' of the enterprise;

Oqai - the number of points marked by the period by a-alternative and q-profile of 'financial health' of the enterprise;

$i$ - the number of the period;

$n-$ the number of periods.

It is necessary to conduct a final evaluation of each ratio for their selection. For this analysis, compliance should be made between the actual indicators for a certain period of time of their standard values. Mismatches between actual and standard values may have two reasons for.

Firstly, the deviations can be purely accidental, caused by accidental factors to investigated issues. Secondly, the difference can be substantial, due to the mismatch of the current situation for each financial indicator of its normal value. The consent criterion - lambda should be used to ensure the objectivity of a comprehensive assessment of the financial health (Kolmogorov, 2009). Actual and normative values of the indicators should be compared in the evaluation process. Then consent criterion - lambda is calculated by the following formula:

$$
\lambda=\frac{D}{\sqrt{\text { Oqai }}}
$$

where $\mathrm{D}$ - maximum value of the accumulated difference between actual and benchmark (or normative, standard) values.

The probability of proximity between the actual and benchmark values for different values of consent criterion (lambda) is determined by using a specially designed table (Kolmogorov, 2009). 
To determine the mean score for each profile formulas of arithmetic mean should be used. To systematize the obtained results Table 3 can be used.

Table 3. Calculation of average of ratings for Financial Statement Assessment Instrument for each financial point

Type of ratios

The period measured: at present / preferred (cross out unnecessary)

\begin{tabular}{cccccc} 
Period & & & & \\
& A & B & C & D & E \\
\hline 1 & & & & & \\
2 & & & & \\
3 & & & \\
$\ldots$. & & & \\
$\mathrm{n}$ & & & \\
Total & & & & \\
\hline Average
\end{tabular}

Building of 'financial health' configuration quantitatively and graphically

Based on the obtained results the profiles of 'financial health' are built as polyhedrons (see the example in Fig. 2) by different financial points (types of ratios) (Liquidity; Profitability; Financial leverage (debt); Valuation and Growth; Activity (Management Efficiency); Coverage).

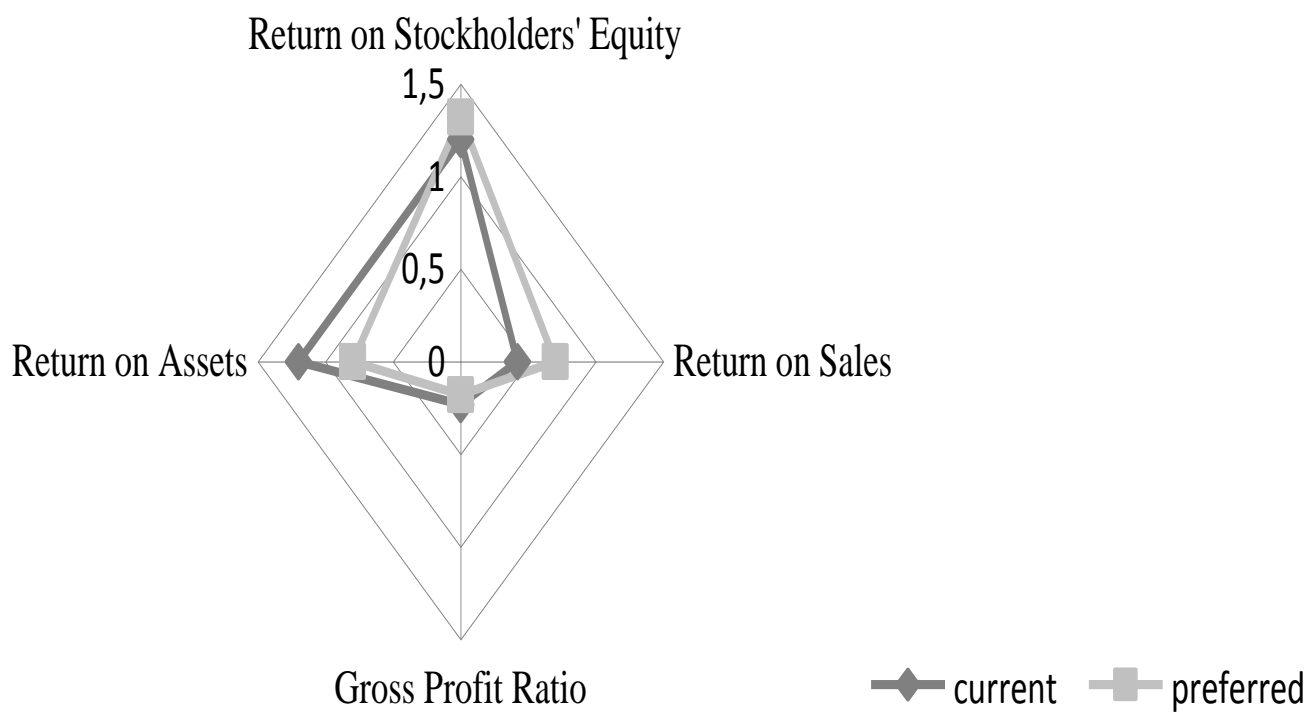

Figure 2. Example of current and preferred 'financial health' profiles by Profitability

The number of corners of each profile corresponds to the number of alternative types of 'financial health' for each financial point. The form of polygons is determined by combining the results of general line of estimates indicated on the diagonals. The solid line represents the current profile of 'financial health' in the company, and the dotted line represents the preferred one for the companies. 
As a result of the use of the FSAI the company receives 12 profiles of 'financial health' (6 current and 6 preferred ones).

Based on the profiles of 'financial health' by different financial points 'financial health' configuration of the enterprise is built, which can be presented graphically depicted in three dimensions, every corner of which corresponds to a defined sign of 'financial health' of the studied enterprise.

The form of polygons is determined by combining the results of the general line of estimates indicated on the diagonals. By the scale $\mathrm{Z}$ (height) the value of rating assessments for each of the alternatives is depicted in the normalized order. In case of three-dimensional image 'financial health' configuration can be schematically represented as Figure 3.

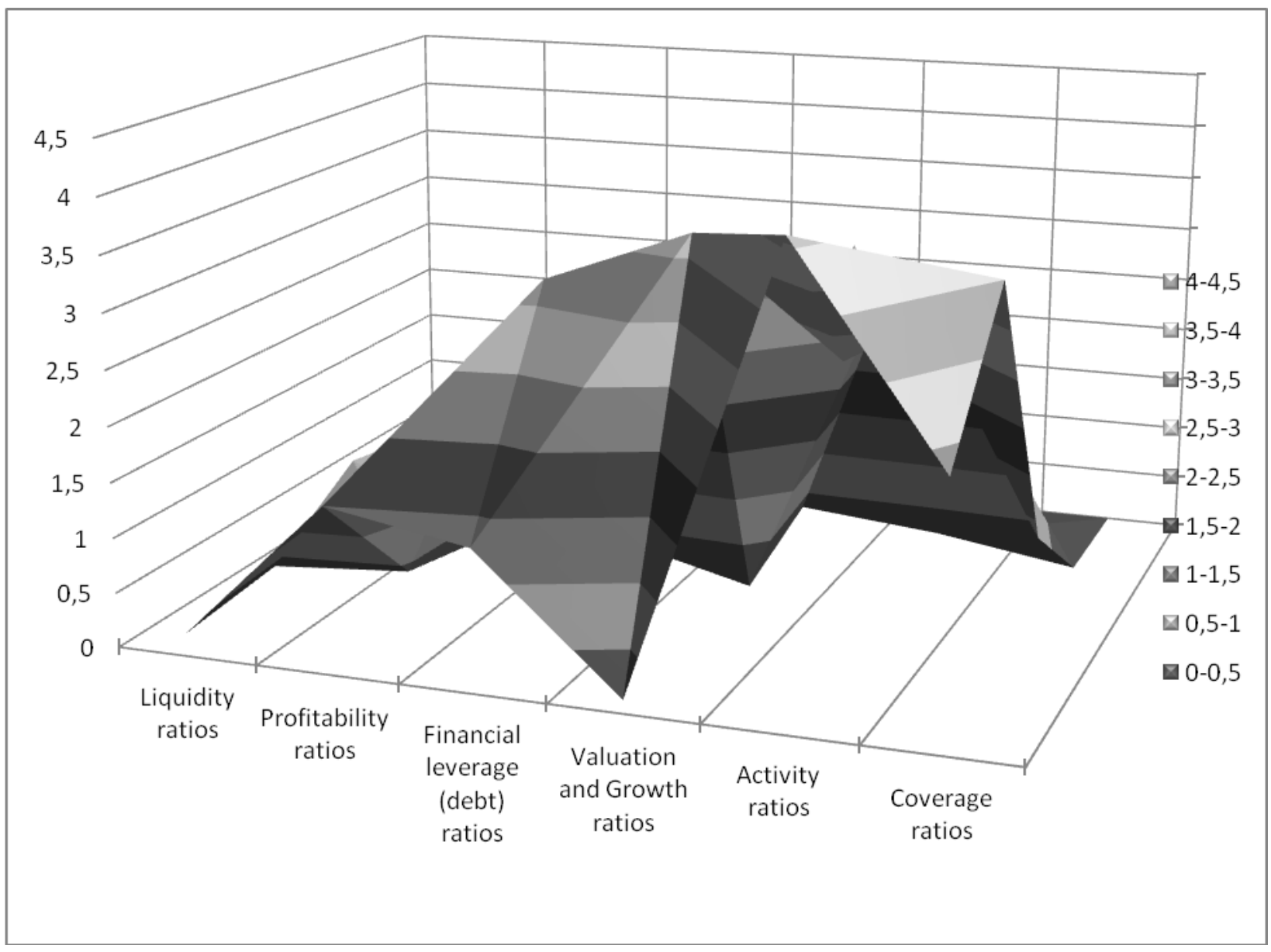

Figure 3. The model of 'financial health' configuration by the designed FSAI

For a comparative analysis of the existing base and 'financial health' configuration at the enterprise it is necessary to make two tables of parameters for 'financial health' configuration by the designed FSAI and builds separate figures for the present and preferred 'financial health' configuration for the investigated company.

At the final stage prerequisites for changing 'financial health' configuration are estimated. For this purpose, it is advisable to use two pyramids with six corners: dominant types of 'financial health' in the company by 6 classification criteria and preferred domination whose example is presented in Figure 4. 


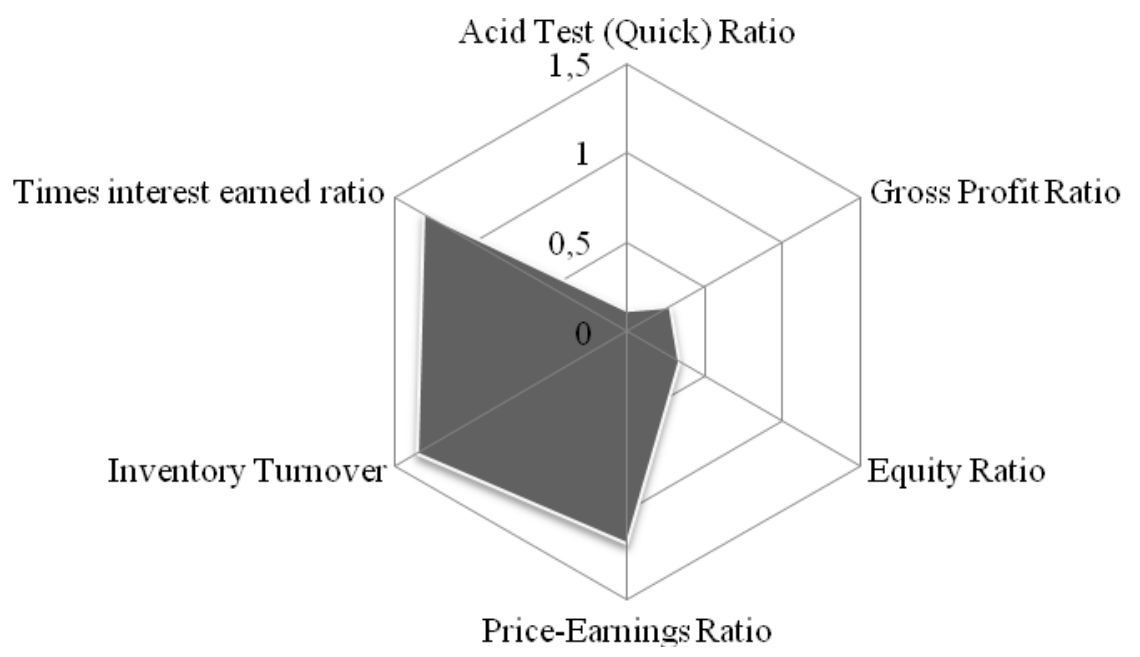

Fig. 4 Example of dominant types of 'financial health' set in the company by the designed FSAI

Using the designed FSAI provides visual information base for decision-making on reformatting 'financial health' configuration taking into account evaluation of the existing forms and determining tendencies of its development.

\section{Conclusions}

The objective of this study was to create special instrument of financial statement analysis to fill the gaps mentioned above by realizing limited results of the financial statement analysis theoretical models, which eliminate comprehensive measurement of financial health. This instrument is aimed to design benchmark assessment as an element of financial statement analysis through determination and investigation of current financial health configuring.

Designed model of 'financial health' configuration is directed to understand how preferred 'financial health' configuration corresponds with the current one. More specifically, we developed the instrument for assessment of financial statement to close the gap between both current and preferred 'financial health' in companies, particularly through visual assessment.

The designed FSAI involves the construction of 'financial health' configuration of the investigated companies and is aimed at performing 6 functions (information, identification, warning, directing, symptomatic, consulting and advisory).

Our study was directed at the systematic analyses of various financial ratios in six groups: Liquidity; Profitability; Financial leverage (debt); Valuation and Growth; Activity (Management Efficiency); Coverage. It is give possibility to build 'financial health' configuration for company quantitatively and graphically. As a result, we show that current 'financial health' is relatively weak and weak points are outlined to close the gap between both current and preferred 'financial health' configuration in the companies.

This analysis could include compliance between the actual indicators for a certain period of time of their benchmark (or normative, standard) values too. In this case, the consent criterion - lambda is proposed to use. It is way to ensure the objectivity of a comprehensive assessment of the financial health. Actual and normative values of the indicators are compared in the evaluation process.

The advantages of the developed 'financial health' configuration assessment instrument are: complexity; pictorial rendition; reasonableness; practical orientation; timeliness; latitude 
involvement; availability for users. Its use provides visual information base for decisionmaking on reformatting 'financial health' configuration.

\section{References}

Al Mamun, A. (2013). Performance Evaluation of Prime Bank Limited in Terms of Capital Adequacy. Global Journal of Management and Business Research, 13 (9).

Altman, E. I. (1968). Financial ratios, discriminant analysis and the prediction of corporate bankruptcy. The journal of finance, 23 (4), pp. 589-609.

Alver, J., Alver, L. (2009). Development of accounting and implementation of international financial reporting standards in Estonia. Accounting Reform in Transition and Developing Economies: Springer US

Barth, M. E., Beaver, W. H., Landsman, W. R. (1998). Relative valuation roles of equity book value and net income as a function of financial health. Journal of Accounting and Economics, 25 (1), pp. 1-34.

Cameron K. S., Quinn R. (2005). Diagnosing and Changing Organizational Culture: Based on the Competing Values Framework. John Wiley \& Sons.

Christensen, H. B., Lee, E., Walker, M., Zeng, C. (2015). Incentives or standards: What determines accounting quality changes around IFRS adoption? European Accounting Review, 24 (1), pp. 31-61.

Cochran, P. L., Wood, R. A. (1984). Corporate social responsibility and financial performance. Academy of management Journal, 27 (1), pp. 42-56.

Deakin, E. B. (1972). A discriminant analysis of predictors of business failure. Journal of accounting research, pp. 167-179.

Desai, H., Rajgopal, S., Yu, J. J. (2015). Were Information Intermediaries Sensitive Financial Statement-Based Leading Indicators of Bank Distress Prior to the Financial Crisis? Contemporary Accounting Research.

Edmister, R. O. (1972). An empirical test of financial ratio analysis for small business failure prediction. Journal of Financial and Quantitative analysis, 7 (02), pp. 1477-1493.

Gibson, C. H. (2012). Financial statement analysis, Thomson South-Western International.

Han, S., Chen, R. C. (2014). Using SVM with Financial Statement Analysis for Prediction of Stocks. Communications of the IIMA, 7 (4), 8.

Horton, J., Serafeim, G., Serafeim, I. (2013). Does mandatory IFRS adoption improve the information environment? Contemporary Accounting Research, 30 (1), pp. 388-423.

Kaplan, R. S., \& Norton, D. P. (1996). Using the balanced scorecard as a strategic management system. Using the Balanced Scorecard as a Strategic Management System. Harvard Business Review, 75, pp.150-161.

Kolmogorov, A. (2009). Kolmogorov criterion. Critical values $\lambda \alpha$ distribution, available online at www.smc.edu.nstu.ru/krit_kolm.htm

Lewellen, J. (2004). Predicting returns with financial ratios. Journal of Financial Economics, 74 (2), pp. 209-235.

Li, K., Mohanram, P. (2014). Fundamental Analysis: A comparison of Financial Statement Analysis Driven and Intrinsic Value Driven Approaches. 
Maystadt, P. (2013). Should IFRS standards be more "European". Mission to reinforce the EU's contribution to the development of international accounting standards. Report to the European Commission.

Ohlson, J. A. (1980). Financial ratios and the probabilistic prediction of bankruptcy. Journal of accounting research, pp. 109-131.

Penman, S. H., Penman, S. H. (2007). Financial statement analysis and security valuation. New York: McGraw-Hill.

Ross, S. A. (1977). The determination of financial structure: the incentive-signalling approach. The bell journal of economics, pp. 23-40.

Schmidlin, N. (2014). The Art of Company Valuation and Financial Statement Analysis: A Value Investor's Guide with Real-life Case Studies. John Wiley \& Sons.

Stickney, C., Brown, P., Press, D. (1990). Financial Statement Analysis. Harcourt Brace Jovanovich.

Vogel, H. L. (2014). Entertainment industry economics: A guide for financial analysis. Cambridge: University Press.

Yermack, D. (1996). Higher market valuation of companies with a small board of directors. Journal of financial economics, 40 (2), pp. 185-211.

Zheng, X., Alver, J. (2015). A Modification of Efficacy Coefficient Model for Enterprise Performance Evaluation. Journal of Applied Management and Investments, 4 (3), pp. 177187. 